\title{
lonic interactions between precipitation and leaf cuticles
}

\author{
T. Scherbatskoy \\ University of Vermont, Botany Department, Burlington, VT 05405, U.S.A.
}

\section{Introduction}

The leaf cuticle is the most important ratelimiting barrier controlling the movement of solutes between precipitation and the leaf interior, but the mechanisms and rates by which ions diffuse through the cuticle remain poorly defined. There is strong experimental evidence that cuticles contain hydratable pores up to $0.45 \mathrm{~nm}$ in radius lined with polar groups (McFarlane and Berry, 1975; Schönherr, 1979; Seymour, 1980). These hydrophilic regions in cuticles probably incorporate the polar substituents of waxes and cutin, as well as polyuronic acids of the polysaccharides in the secondary cuticle. These polar groups and polar pores are likely to contribute greatly to the ion exchange capacity and transport properties of cuticles. This research examined the ionic interactions between leaf surfaces and precipitation, particularly the role of the leaf cuticle in mediating ion transport into and out of the leaves.

\section{Materials and Methods}

\section{lonic exchange}

Individual $50 \mu \mathrm{l}$ drops of artificial precipitation representing regional ambient precipitation at
$\mathrm{pH} 3.8$ or 5.4 were applied to adaxial and abaxial surfaces of mature, field-grown Acer saccharum leaves which had been rinsed with deionized water. Ten experiments were conducted at weekly intervals between July and September in a high-humidity chamber to reduce drop evaporation. Drops were quantitatively removed after precise times between 4 and $128 \mathrm{~min}$ and analyzed for $\mathrm{Cu}^{2+}, \mathrm{Pb}^{2+}, \mathrm{Zn}^{2+}$, $\mathrm{K}+, \mathrm{Ca}^{2+}$ and $\mathrm{Mg}^{2+}$.

\section{Electrophysiology}

Adaxial cuticles were enzymatically isolated (Orgell, 1955) from mature leaves of several tree species. Diffusion potentials across cuticles were measured in a flow-cell by pumping unbuffered salt solutions across the two sides of the cuticle to create ion concentration gradients. Electrical potentials across the cuticle were measured for various concentration ratios, $C_{1} / C_{0}$, and were expressed as $E^{\text {io }}=\left(\psi^{i}-\psi^{\circ}\right)$, where $\psi$ is the local voltage and the superscripts refer to inside and outside the cuticle.

\section{Results}

Concentrations of $\mathrm{Cu}^{2+}$ and $\mathrm{Pb}^{2+}$ remaining in applied solutions declined rapidly with time at pH 5.4 (Fig. 1); this was more pronounced on adaxial leaf surfaces. Concentrations of $\mathrm{Zn}^{2+}$ were unchanged under all treatments. $\mathrm{K}^{+}, \mathrm{Ca}^{2+}$ and $\mathrm{Mg}^{2+}$ 

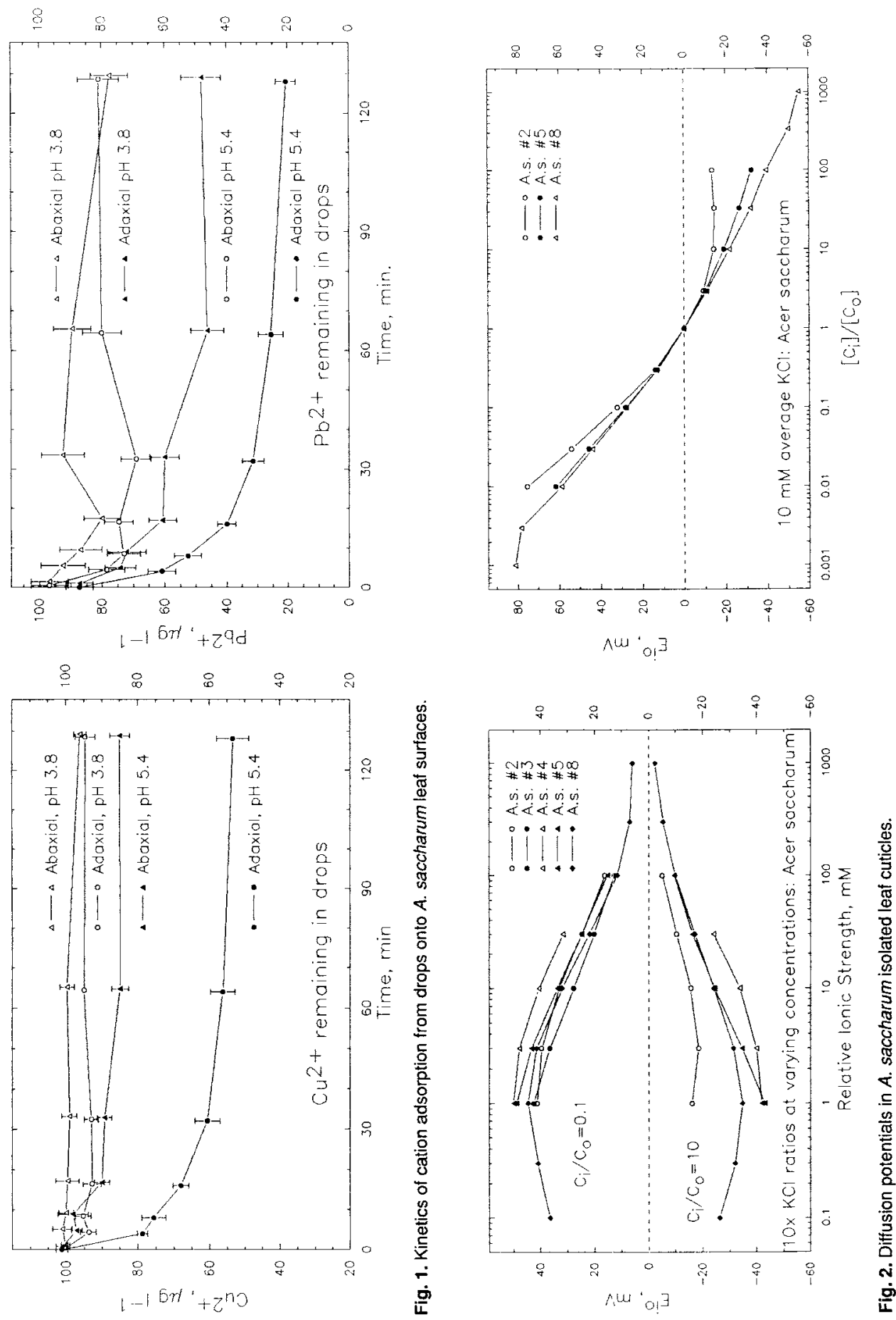
tended to increase with time, more so at pH 3.8.

Diffusion potentials are graphed in Fig. 2 for $A$. saccharum in $\mathrm{KCl}$ under 2 experimental regimes: 1) constant 10-fold concentration ratios at different ionic strengths, and 2) constant average ionic strength $(10 \mathrm{mM})$ at different concentration ratios. These graphs show 2 important responses typical for all species: diffusion potentials increased with decreasing ionic strength, and potentials were asymmetric, being smaller when $C_{\mathrm{i}} / C_{0}>1$.

\section{Discussion and Conclusion}

In the ion exchange experiments, adsorption of $\mathrm{Cu}^{2+}$ and $\mathrm{Pb}^{2+}$ was reduced at the lower $\mathrm{pH}$. This is consistent with a reduction in available exchange sites for cation adsorption at the higher $\mathrm{H}_{3} \mathrm{O}^{+}$concentration. Increased $\mathrm{H}_{3} \mathrm{O}^{+}$concentration, on the other hand, would favor the release of $\mathrm{K}^{+}$, $\mathrm{Ca}^{2+}$ and $\mathrm{Mg}^{2+}$ from adsorption sites on the leaf surface.

The kinetics in these experiments can be used to predict cuticular permeability coefficients $(P)$ that would be required if this was the only exchange mechanism operating. This leads to apparent cuticular $P=10^{-5}$ and $10^{-4} \mathrm{~cm} \cdot \mathrm{s}^{-1}$ for $\mathrm{Cu}^{2+}$ and $\mathrm{Pb}^{2+}$, respectively. These are much too large to represent cuticular permeation, suggesting instead that surface adsorption mechanisms dominate. For $\mathrm{K}^{+}, \mathrm{Ca}^{2+}$ and $\mathrm{Mg}^{2+}$, on the other hand, the calculated apparent $P \mathrm{~S}$ are similar to those measured in isolated cuticles (McFarlane and Berry, 1974; Reed and Tukey, 1982). These rates suggest a different mechanism may be operating for these cations. It is possible in this case that prerinsing the leaves may have removed most of the exchangeable $\mathrm{K}^{+}, \mathrm{Ca}^{2+}$ and $\mathrm{Mg}^{2+}$ from the surface, so that cuticular permeation was mostly responsible for the efflux of these cations into solutions. Using published $P \mathrm{~S}$ to predict exchange times, calculations show that half-times for cation exchange between the apoplast and precipitation by cuticular permeation is about 10 days.

In the electrophysiology experiments, diffusion potentials approached $\pm 59 \mathrm{mV}$ at low ionic strength when the concentration ratio was 0.1 or 10 (Fig. 2), confirming the Nernstian behavior of this system. The increase in potential with decreasing ionic strength indicates that the permeability ratio, $P_{\text {cation }} / P_{\text {anion }}$ increased as ionic strength decreased; this was due to ionic partition coefficients changing with ionic strength. The asymmetry of the potentials varied among cuticles and appeared to be caused by the asymmetric distribution of negative charge in the cuticle.

Potentials were inadequately modeled by the Goldman equation, apparently due to changing permeability ratios within the cuticle. Pure cellulose membranes (presumed to be more structurally homogeneous than cuticles) did allow a good fit between predicted and observed potentials (Fig. 3 ).

The importance of electrical potential was evaluated by comparing the driving force for ionic flux due to: 1) only chemical potential, or 2) electrochemical potential. Potentials were measured while mimicking natural conditions by applying artificial acidic precipitation to the outside of the cuticle and artificial apoplastic solution to the inside. At pH 3.8, there was little difference in the driving force between the two models. At pH 5.4, however, ignoring the electrical potential resulted in overestimating the driving force for cations by a factor of 2.

This work showed that cuticular permeation and ion exchange between precipitation and the leaf apoplast do not occur at biologically significant rates. Instead, ion exchange processes with the leaf cuticle 

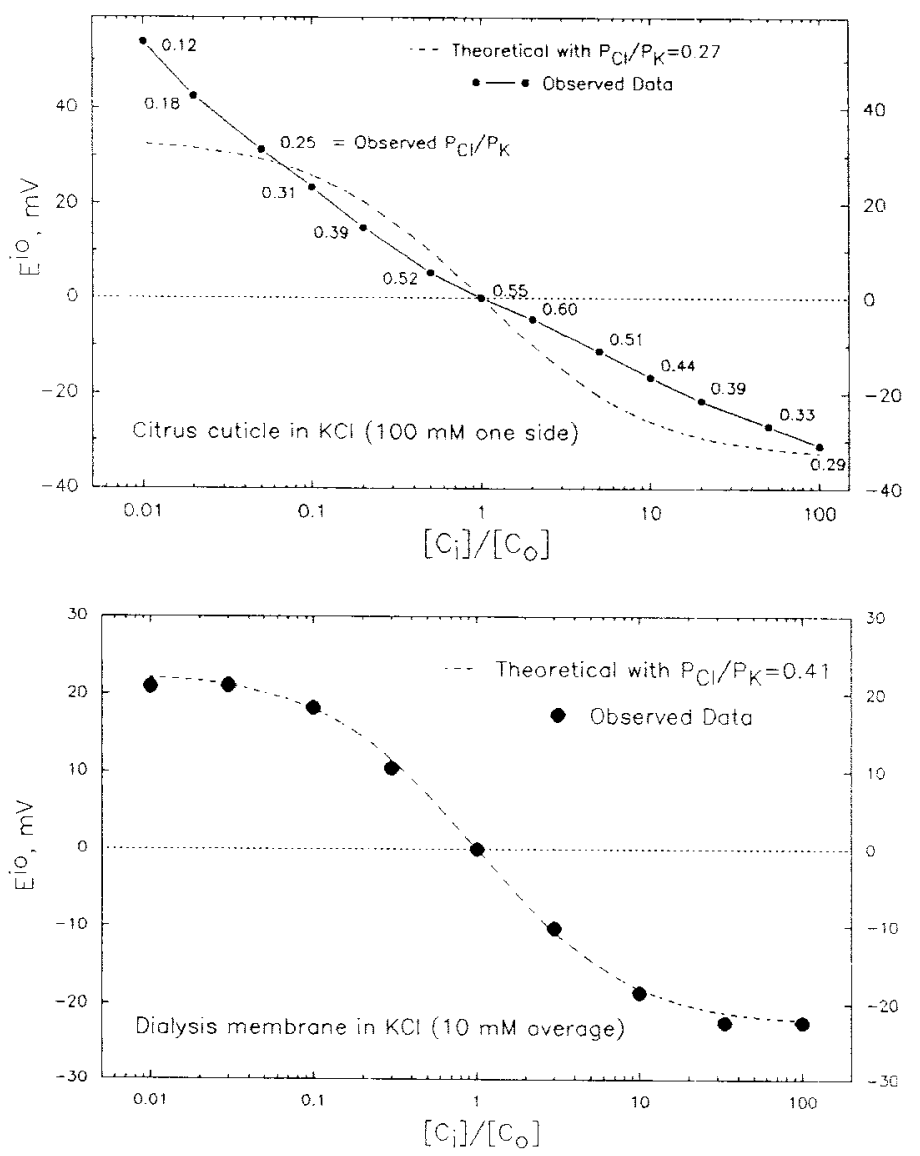

Fig. 3. Observed vs predicted diffusion potentials.

surface dominate. Electrophysiology studies showed that significant diffusion potentials can arise across cuticles and these can have a significant effect on ionic flux. Furthermore, ionic permeability in cuticles varied with both ionic strength and cuticle structure.

\section{References}

McFarlane J.C. \& Berry W.L. (1974) Cation penetration through isolated leaf cuticles. Plant Physiol. 53, 723-727

Orgell W.H. (1955) The isolation of plant cuticle with pectic enzymes. Plant Physiol. 30, 78-80
Reed D.W. \& Tukey H.B. (1982) Permeability of Brussels sprouts and carnation cuticles from leaves developed in different temperatures and light intensities. In: The Plant Cuticle. (Cutler D.F., Alvin K.L. \& Price C.E., eds.), Linnean Society of Lonclon International Symposium, London, 8-11 Sept. 1980. Academic Press, London, pp. 267-278

Schönherr J. (1979) Transcuticular movement of xenobiotics. In: Advances in Pesticide Science (Geissbuhler H., Brooks G.T. \& Kearne P.C., eds.). Papers from the Fourth International Congress of Pesticide Chemistry, Zurich, 24-28 July 1978. Pergamon, Oxford, pp. 392-400

Seymour V.A. (1980) Leaf cuticle: an investigation of some physical and chemical properties derived from a study of Berberis. Ph.D. Thesis, University of Washington, Seattle 